\title{
Unusual presentation of adult xanthogranuloma
}

Tan LX, Aw CW

Singapore Med J 2014; 55(2): e25-e27; http://dx.doi.org/10.11622/smedj.2013207

The authors wish to add Tan Kong Bing to the author list of this case report for being the pathologist involved in reporting the patient's skin biopsy, and for having contributed significantly to the clinicopathological discussion of the case. He had also personally prepared the histological images and annotations, and provided valuable input with respect to the main text of the report. The complete author and affiliations lists are as follows:

Lixian Chris $\underline{\operatorname{Tan}}^{1}$, MBBS, Kong Bing $\underline{\operatorname{Tan}}{ }^{2}$, FRCPA, FRCPath, Chen Wee Derrick $\underline{A w^{1}}$, MBBS, MRCP

${ }^{1}$ Division of Dermatology, ${ }^{2}$ Department of Pathology, National University Hospital, Singapore

doi: $10.11622 /$ smedj.2014047 